\title{
SUPLEMENTACIÓN CON HARINA DE BANANO SOBRE LA GANANCIA DE PESO EN NOVILLAS JERSEY1
}

\author{
Claudio Fabián Vargas-Rodríguez ${ }^{2}$, Carlos Boschini-Figueroa ${ }^{2}$
}

\begin{abstract}
RESUMEN
Suplementación con harina de banano sobre la ganancia de peso en novillas Jersey. El experimento se realizó entre los meses de febrero y mayo del año 2005, en la Estación Experimental Alfredo Volio Mata de la Universidad de Costa Rica, con la intención de probar la harina de banano como fuente alternativa de energía en la alimentación de novillas Jersey en desarrollo. Se estimó la ganancia de peso de 15 animales mediante la metodología de cuadrados latinos repetidos (cinco grupos) asignados de acuerdo a su peso corporal, los cuales fueron alimentados con dietas que contenían tres niveles de harina de banano $(0,00 \%, 0,33 \%$ y $0,66 \%$ de Peso Vivo). Los mejores resultados se obtuvieron con el nivel de inclusión intermedio $(0,33 \%)$ y se estimó que al agregar dosis mayores a $0,36 \%$ PV disminuye la ganancia de peso por día, lo que no justifica la suplementación más allá de ese punto.
\end{abstract}

Palabras clave: Harina de banano, ganado de leche, novillas de reemplazos, ganancia de peso, nutrición.

\begin{abstract}
Supplementation with banana flour on the profit of weigh in Jersey heifers. The experiment was carried out at Experimental Station "Alfredo Volio Mata" of the University of Costa Rica from February to May 2005 with the objective of proving banana flour as an alternative energy source for the nutrition of growing Jersey heifers. There was estimated the weigh of 15 animals, using repeated Latin square methodology (five groups), and fed with three different levels of banana flour $(0,00 \%, 0,33 \%$ and $0,66 \%$ of Body Weigh). The best results were obtained with the intermediate level of incorporation $(0,33 \%)$, and it is concluded that doses higher than $0,36 \% \mathrm{BW}$ diminishes the profit of weight per day, which does not justify the supplementation beyond this point.
\end{abstract}

Key words: Banana flour, dairy cattle, replacement heifers, weight gain, nutrition.

\section{INTRODUCCIÓN}

La dependencia de alimentos concentrados, para el crecimiento de reemplazos y la alimentación de vacas lecheras de alto potencial genético, parece inevitable, particularmente, cuando se pretenden altos rendimientos de producción en animales alimentados con forrajes tropicales. Cerca de un $20 \%$ de los costos de producción en las explotaciones lecheras se atribuyen a la crianza y alimentación de reemplazos (Pirlo et al. 1997), observándose un marcado efecto negativo sobre la rentabilidad del hato conforme aumenta el número de novillas producidas anualmente (Wattiaux 2003).

La productividad de la explotación puede ser alterada de modo contraproducente por un desarrollo retardado en los animales. La pubertad y la producción de leche en la primera lactancia están más asociados con

\footnotetext{
1 Recibido: 4 de abril, 2006. Aceptado: 5 de marzo, 2007. Trabajo financiado por la Vicerrectoría de Investigación. Proyecto 737-97-006. Universidad de Costa Rica.

2 Estación Experimental Alfredo Volio Mata. Facultad de Ciencias Agroalimentarias. Universidad de Costa Rica. Correo electrónico: fvargasr@cariari.ucr.ac.cr; boschini@cariari.ucr.ac.cr
} 
el peso corporal que con cualquier otro factor simple en la vida de las novillas (Salvador 2002), razón por la que actualmente los programas eficientes de manejo de reemplazos tienen como objetivo alcanzar tasas de crecimiento que permitan el primer apareamiento de las hembras a edades tempranas (13 - 15 meses), de manera tal que se maximiza el potencial de todo el rebaño (McGuirk y Ruegg 2005).

Para lograr que el animal exprese su habilidad productiva y potencial genético, se hace indispensable centrar especial atención a la parte nutricional, enfocado en aportar los elementos necesarios y la cantidad adecuada de nutrientes de acuerdo a la edad y capacidad de ingestión del animal. Candanedo y Arauz (1997) destacan en un estudio realizado con novillas Holstein en crecimiento, que la energía fue el elemento más limitante durante los primeros 24 meses de edad; sin embargo, nutrimentos como proteínas, minerales, vitaminas y fibra cruda, no deben ser descuidados para lograr un balance adecuado en las dietas empleadas (Blanco et al. 2003).

No obstante, con frecuencia la normativa ha sido delegar la alimentación de terneras y novillas a áreas de pastoreo donde la fuente forrajera es de baja calidad, lo que genera insuficiencias nutricionales que retrasan el crecimiento y la iniciación de la actividad reproductiva, causando que el primer parto se presente en edades superiores a 24 meses, afectando la cantidad de leche total en la vida productiva del animal (Salvador 2002). Además, Pulido et al. (2002) indican que dietas que utilizan forraje como única fuente de nutrientes no logran satisfacer todas las demandas de las vacas lecheras de alta producción, efecto que respalda Obispo et al. (2002) al mencionar que generalmente los aportes forrajeros son deficientes en energía, proteína, minerales y vitaminas.

Es por esta razón que las alternativas de suplementación son las más viables para mejorar la dieta (Birbe et al. 1997), sobre todo tomando en cuenta la naturaleza de la proteína de los forrajes y su degradabilidad, lo que fomenta la necesidad de complementos energéticos que optimicen su utilización (Pulido et al. 2002).

El maíz es la materia prima de mayor demanda en la industria de alimentos concentrados como principal fuente de energía, su contenido ronda las 3,38 Mcal/ $\mathrm{kg}$ de $\mathrm{EM}^{3}$ (Pulido et al. 2002). Sumado a esto, se considera que el $40 \%$ del contenido de almidones llega al intestino sin ser degradado (Thompson et al. 1999) y el restante $60 \%$ se fermenta lentamente, mejorando el crecimiento bacterial (Pulido et al. 2002). En la franja centroamericana, la producción de grano de maíz es principalmente para consumo humano y la incorporación de éste en los alimentos balanceados para animales es un producto importado, razón por la cual se justifica la búsqueda y evaluación de nuevas alternativas energéticas que contribuyan en el crecimiento y desarrollo de novillas de reemplazo. Por otro lado, en las explotaciones bananeras, una proporción entre 4 y $50 \%$ del banano producido no alcanza los estándares de exportación (FAO 2005), siendo una parte utilizada en la fabricación de puré para infantes (Chiquita 1998).

El remanente de las explotaciones bananeras, constituye un desecho con un alto contenido de carbohidratos fermentables y un bajo contenido de proteína cruda. Con esas características, el banano de rechazo industrial es una fuente de energía aprovechable en la alimentación de animales. El presente trabajo tuvo el propósito de evaluar la ganancia de peso en novillas Jersey alimentadas con diferentes niveles de suplementación de harina de banano en la dieta total.

\section{MATERIALES Y MÉTODOS}

\section{Localización}

La investigación se efectuó entre los meses de febrero y mayo del 2005, en la Estación Experimental de Ganado Lechero Alfredo Volio Mata de la Universidad de Costa Rica, ubicada a $1.542 \mathrm{msnm}$, en Ochomogo de Cartago. La temperatura media anual es de $19,5{ }^{\circ} \mathrm{C}$ y la humedad relativa media es de $84 \%$ con una precipitación media de $2.050 \mathrm{~mm}$.

\section{Materiales experimentales}

En el experimento se emplearon 15 novillas Jersey con edades entre 11 y 19 meses, y un rango de peso vivo entre 176 y $352 \mathrm{~kg}$, agrupadas en cinco grupos

\footnotetext{
3 Energía Metabolizable.
} 
experimentales, balanceados internamente por edad y peso. Las novillas fueron mantenidas bajo estabulación completa durante toda la fase experimental de 90 días.

Todas las novillas recibieron una ración total compuesta por alimento concentrado en una cantidad proporción de $1 \%$ del peso vivo, más forraje hasta complementar la dieta total. Los tratamientos experimentales consistieron en la inclusión de harina de banano en el alimento concentrado, en tres proporciones: 0, 0,33 y $0,66 \%$ del peso vivo. Cada dieta experimental fue balanceada en forma isocalórica e isoproteica para reunir la concentración de nutrientes recomendados por el National Research Council (NRC 2001) para ganado lechero, en cada grupo de edad. Para complementar la dieta total se suministró ensilado de maíz como fuente forrajera a libre consumo. Adicionalmente, se suministró agua y una mezcla de sales minerales.

Las fuentes empleadas para elaborar las dietas experimentales se detallan en el Cuadro 1, donde se indica la composición química de cada una.
Cuadro 1. Alimentos empleados en las dietas experimentales. Cartago, Costa Rica. 2005.

\begin{tabular}{lrrr}
\hline Fuentes $^{1}$ & $\begin{array}{c}\text { Materia } \\
\text { seca \% }\end{array}$ & $\begin{array}{c}\text { Proteína } \\
\text { cruda \% }\end{array}$ & $\begin{array}{c}\text { Energía neta } \\
\text { Mcal/kg }\end{array}$ \\
\hline Concentrado comercial & 87,00 & 14,00 & 1,65 \\
Harina de banano & 90,00 & 5,00 & 1,70 \\
Urea & 100,00 & 287,50 & 0,00 \\
Ensilaje de maíz & 25,00 & 7,00 & 1,10 \\
\hline
\end{tabular}

${ }^{1}$ Fuentes analizadas en el Laboratorio de Bromatología de la Estación Experimental de Ganado Lechero Alfredo Volio Mata, Universidad de Costa Rica.

Se empleó un diseño de cuadrados latinos repetidos, donde se asignaron tres animales por cada cuadrado latino en cinco repeticiones experimentales (Steel y Torrie 1980). Cada repetición agrupó novillas con los siguientes pesos promedios: 335, 269, 217, 196 y $182 \mathrm{~kg}$. Los tres tratamientos experimentales con diferentes niveles de inclusión de harina de banano se detallan en el Cuadro 2. Cada dieta experimental fue

Cuadro 2. Tratamientos experimentales aplicados en cada cuadrado latino. Cartago, Costa Rica. 2005

\begin{tabular}{|c|c|c|c|c|c|}
\hline \multirow[b]{2}{*}{ Tratamientos } & \multicolumn{5}{|c|}{ Cuadrados latinos } \\
\hline & G1 & G2 & G3 & G4 & G5 \\
\hline \multicolumn{6}{|l|}{$0,00 \% \mathrm{HB} / \mathrm{PV}$} \\
\hline Consumo ofrecido de MS, kg/día & 3,35 & 2,69 & 2,17 & 1,96 & 1,82 \\
\hline Concentrado comercial, kg MS/día & 3,35 & 2,69 & 2,17 & 1,96 & 1,82 \\
\hline Harina de banano, kg MS/día & 0 & 0 & 0 & 0 & 0 \\
\hline Urea, g MS/día & 0 & 0 & 0 & 0 & 0 \\
\hline EN, mcals/día & 5,53 & 4,44 & 3,58 & 3,23 & 3,00 \\
\hline PC, g/día & 408 & 328 & 264 & 239 & 222 \\
\hline \multicolumn{6}{|l|}{$0,33 \% \mathrm{HB} / \mathrm{PV}$} \\
\hline Consumo ofrecido de MS, kg/día & 3,33 & 2,68 & 2,16 & 1,95 & 1,81 \\
\hline Concentrado comercial, kg MS/día & 2,23 & 1,79 & 1,45 & 1,31 & 1,21 \\
\hline Harina de banano, kg MS/día & 1,08 & 0,87 & 0,70 & 0,63 & 0,59 \\
\hline Urea, g MS/día & 22,72 & 18,24 & 14,72 & 13,28 & 12,32 \\
\hline EN, mcals/día & 5,52 & 4,43 & 3,58 & 3,23 & 3,00 \\
\hline PC, g/día & 432 & 347 & 280 & 253 & 234 \\
\hline \multicolumn{6}{|l|}{$0,66 \% \mathrm{HB} / \mathrm{PV}$} \\
\hline Consumo ofrecido de MS, kg/día & 3,34 & 2,68 & 2,16 & 1,94 & 1,81 \\
\hline Concentrado comercial, kg MS/día & 1,12 & 0,90 & 0,72 & 0,65 & 0,61 \\
\hline Harina de banano, kg MS/día & 2,16 & 1,73 & 1,40 & 1,26 & 1,17 \\
\hline Urea, g MS/día & 56,80 & 45,60 & 36,80 & 33,20 & 30,85 \\
\hline EN, mcals/día & 5,52 & 4,43 & 3,57 & 3,21 & 3,00 \\
\hline PC, g/día & 428 & 344 & 277 & 249 & 233 \\
\hline
\end{tabular}

HB: Harina de banano, PV: peso vivo de los animales. 
elaborada en una mezcladora para concreto, con capacidad para mezclar $200 \mathrm{~kg}$ de alimento animal.

Dentro de cada grupo de novillas (repeticiones de cuadrado latino) se asignó un tratamiento a cada animal durante un periodo de 30 días, con 15 días iniciales de adaptación y los siguientes 15 días de evaluación. Se incluyeron tres periodos experimentales. Al término de cada uno se procedió a cambiar el tratamiento de cada animal dentro de cada cuadrado latino.

Las quince novillas fueron estabuladas en un galerón de investigación con comederos individuales. La cantidad diaria de dieta experimental para cada animal se ofreció en dos tantos iguales, una a las 7:00 am y la otra a las 2:00 pm, como alimento único hasta su total consumo, y posteriormente se ofreció ad libitum el complemento forrajero de ensilaje de maíz. Cada comedero contó con un bebedero automático.

Al inicio y final de cada periodo de adaptación y de evaluación, se pesaron las novillas utilizando una romana para pesar ganado, calibrada, marca $\mathrm{Ag}$ Tronic, Inc, con capacidad de $1.400 \mathrm{~kg}$, para cuantificar la ganancia de peso en cada periodo experimental debido a la inclusión de la harina de banano en las dietas propuestas. Los datos de ganancia de peso fueron analizados con el PROC ANOVA de SAS, versión 8.2 (SAS 1999). La prueba de medias se efectuó mediante una comparación de Duncan.

\section{RESULTADOS Y DISCUSIÓN}

$\mathrm{Al}$ analizar los resultados obtenidos, se observa en el Cuadro 3 las diferencias significativas $(\mathrm{P}<0,01)$ en peso corporal promedio y ganancia de peso por día entre las novillas agrupadas en cuadrados latinos (repeticiones). Se aprecia que los animales con pesos promedio de $229,72 \mathrm{~kg}$ (C5) obtuvieron la ganancia mayor con $0,579 \mathrm{~kg} /$ día, seguido de los animales con pesos de 324,5 (C2) y $369,33 \mathrm{~kg}$ (C1) los cuales sobrepasaron el rango de $0,500 \mathrm{~kg} /$ día. Esos valores se asemejan mucho con lo expresado por Wattiaux (2003), quien indica que novillas Jersey deben ganar peso a razón de $0,500 \mathrm{~kg} /$ día bajo prácticas intensivas de manejo en climas templados, pero difiere con lo
Cuadro 3. Promedio de peso vivo y ganancia de peso por cuadrado latino. Cartago, Costa Rica, 2005.

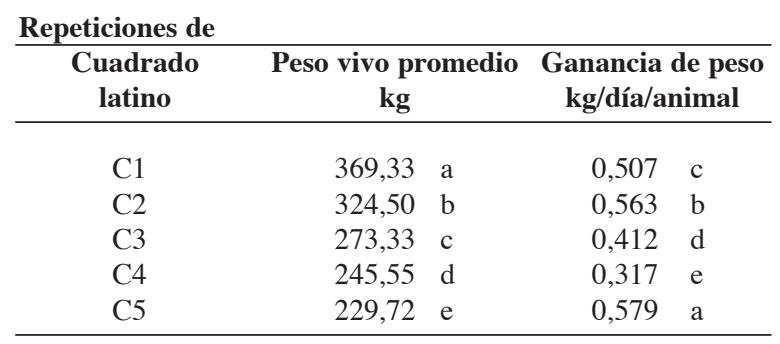

$\mathrm{a}, \mathrm{b}, \mathrm{c}, \mathrm{d}$, e entre filas muestran diferencias significativas $(\mathrm{P}<0,05)$.

indicado por Romero (2005) quien aduce que las novillas con pesos menores de $340 \mathrm{~kg}$ tienen una ganancia de hasta 0,800 kg/día. Pirlo et al. (1997) indican que la producción de leche durante la primera lactancia es menor cuando la ganancia de peso sobrepasa los 0,600 $\mathrm{kg} / \mathrm{día}$ durante la etapa de crecimiento previo.

El periodo de evaluación tuvo impacto sobre el promedio de ganancia de peso de las novillas en crecimiento, observándose variaciones significativas $(\mathrm{P}<0,05)$. Durante el primer periodo los animales tuvieron un peso promedio de $277,47 \mathrm{~kg}$, la ganancia durante esa etapa fue de $0,419 \mathrm{~kg} / \mathrm{dí} / \mathrm{animal}$. En el siguiente periodo el peso promedio de las novillas fue de $287,94 \mathrm{~kg}$, en esta fase se manifestó la mayor ganancia de peso, los animales alcanzaron una tasa de $0,552 \mathrm{~kg} / \mathrm{día} / \mathrm{animal}$; durante el tercer periodo experimental, la ganancia fue inferior al periodo anterior pero ligeramente mayor a la etapa inicial, como lo indica el Cuadro 4.

Cuadro 4. Promedio de peso vivo y ganancia de peso por periodo. Cartago, Costa Rica, 2005.

\begin{tabular}{|c|c|c|}
\hline Periodos & $\begin{array}{c}\text { Peso vivo promedio } \\
\text { kg }\end{array}$ & $\begin{array}{c}\text { Ganancia de peso } \\
\text { kg/día/animal }\end{array}$ \\
\hline 1 & $277,47 \mathrm{c}$ & $0,419 \mathrm{c}$ \\
\hline 2 & $287,94 \quad b$ & $0,552 \quad \mathrm{a}$ \\
\hline 3 & 298,87 a & $0,457 \quad \mathrm{~b}$ \\
\hline
\end{tabular}

a, b, c entre filas muestran diferencias significativas $(\mathrm{P}<0,05)$. 
Al analizar las diferencias entre los animales asignados como uno, dos y tres en cada repetición de cuadrado latino (Cuadro 5), se observaron variaciones importantes $(\mathrm{P}<0,01)$. La mayor diferencia en peso vivo promedio se dio entre el grupo de animales dos y tres; sin embargo, en cuanto a ganancia diaria, el grupo de novillas tres con el menor promedio de peso vivo $(280 \mathrm{~kg})$ tuvo el mejor aprovechamiento de las dietas, presentando la mayor ganancia de peso diaria $(0,571 \mathrm{~kg} /$ día/animal $)$, con una diferencia de 0,238 $\mathrm{kg} /$ día/animal sobre el grupo de novillas uno.

Cuadro 5. Promedio de peso vivo y ganancia de peso por animal. Cartago, Costa Rica, 2005.

\begin{tabular}{ccccc}
\hline Animales & $\begin{array}{c}\text { Peso vivo promedio } \\
\text { kg/animal }\end{array}$ & $\begin{array}{c}\text { Ganancia de peso } \\
\text { kg/día/animal }\end{array}$ \\
\hline 1 & 291,47 & ab & 0,333 & $\mathrm{c}$ \\
2 & 293,10 & a & 0,524 & $\mathrm{~b}$ \\
3 & 280,20 & $\mathrm{~b}$ & 0,571 & $\mathrm{a}$ \\
\hline
\end{tabular}

a, b, c entre filas muestran diferencias significativas $(P<0,05)$.

La suplementación con diferentes niveles de harina de banano, como se observa en el Cuadro 6, no mostró efecto diferenciado ( $\mathrm{P}>0,05)$ sobre el peso promedio final de los animales; sin embargo, al cuantificar el efecto de la inclusión de diferentes niveles de harina de banano en la dieta sobre la ganancia diaria de peso

Cuadro 6. Promedio de peso vivo y ganancia de peso por tratamiento. Cartago, Costa Rica, 2005.

\begin{tabular}{|c|c|c|}
\hline $\begin{array}{c}\text { Tratamiento }^{/ 1} \\
\text { H. Banano } \\
\% / \text { PV }\end{array}$ & $\begin{array}{c}\text { Peso promedio } \\
\text { kg }\end{array}$ & $\begin{array}{c}\text { Ganancia de peso } \\
\text { kg/día }\end{array}$ \\
\hline 0,00 & 290,33 a & $0,391 \quad \mathrm{c}$ \\
\hline 0,33 & 286,40 a & $0,581 \quad \mathrm{a}$ \\
\hline 0,66 & 287,53 a & $0,457 \quad b$ \\
\hline
\end{tabular}

11 Consumo de materia seca de harina de banano, sustituto del concentrado, en relación porcentual al peso vivo.

a, b, c entre filas muestran diferencias significativas $(\mathrm{P}<0,05)$. de las novillas, se logran apreciar diferencias significativas muy importantes $(\mathrm{P}<0,01)$. Los animales que consumieron un $0,33 \%$ del $\mathrm{PV}^{4}$ en harina de banano lograron los mejores rendimientos, su ganancia de peso se dio a una tasa de $0,581 \mathrm{~kg} /$ día/animal, equivalente a 0,190 kg/día/animal más que en el nivel de $0 \%$ del PV (48,6\% de incremento) y $0,124 \mathrm{~kg} /$ día/animal más que en el nivel de $0,66 \%$ del PV (27,1\% de incremento).

En la Figura 1 se observa la forma asimétrica en que se incrementó la ganancia de peso de las novillas conforme aumentó el nivel de participación de la harina de banano en las dietas experimentales. La adición de harina de banano aumentó la ganancia diaria hasta el nivel de $0,36 \% \mathrm{PV}$, siendo éste el máximo favorable, ya que a partir de ese nivel la ganancia de peso diaria decreció a razón de 28,9 g por cada $0,01 \%$ del PV de adición de harina de banano en la dieta. Niveles mayores a $0,36 \%$ PV perjudican la relación beneficio/costo; además, de que podría resultar contraproducente y desventajosa, con consecuencias sobre el adecuado desarrollo y comprometer eventualmente la producción de leche posteriormente (Wattiaux 2003; Lammers y Heinrich 2000).

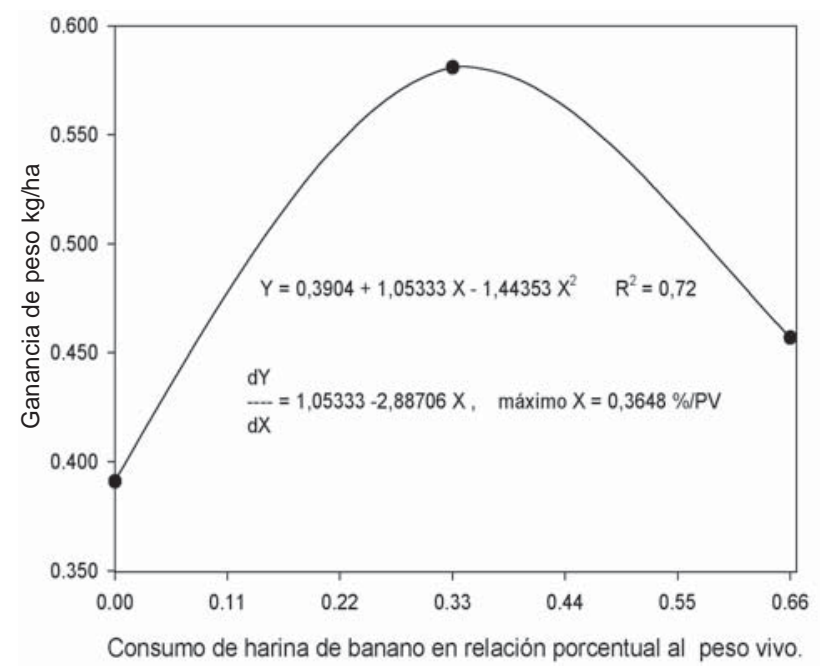

Figura 1. Ganancia de peso de acuerdo a los niveles de consumo de harina de banano. Ochomogo, Cartago, Costa Rica. 2005.

${ }^{4} \mathrm{PV}=$ peso vivo del animal. 


\section{CONCLUSIONES}

La harina de banano con adecuada suplementación de $\mathrm{N}$, es una excelente fuente de energía para la alimentación de novillas de reemplazo.

A un nivel de inclusión en la dieta de $0,36 \%$ del PV se logran las mejores ganancias de peso por día.

Cantidades de harina de banano superiores a 0,36 $\%$ del PV no generan mayores ganancias de peso, por el contrario la ganancia tiende a disminuir, y puede representar un costo adicional.

\section{RECOMENDACIÓN}

Se debe examinar el costo de la elaboración de harina de banano para conocer si realmente es rentable utilizar esta fuente como materia prima en la alimentación animal.

\section{LITERATURA CITADA}

BIRBE, B.; HERRERA, P.; HERNÁNDEZ, N.; MATA, D. 1997. Manejo de novillas suplementadas en condiciones de sabana. Comportamiento reproductivo a dos edades de suplementación con bloques multinutricionales. Archivo Latinoamericano. Producción Animal 5 (1): 212-213

BLANCO, M.; MALAVER, M.; PEZO, S. 2003. Manual práctico de ganadería: alimentación animal, sanidad animal, mejoramiento ganadero. Lima, Perú. Ed. ITDG. 51p.

CANDANEDO, E.; ARAÚZ, E. 1997. Evaluación del sistema de crianza y el desempeño de novillas Holstein bajo condiciones comerciales y tecnificadas en fincas lecheras especializadas en Panamá. Archivo Latinoamericano. Producción Animal 5 (1): 641-644.

CHIQUITA. 1998. Chiquita en Costa Rica, un siglo de desarrollo y progreso. (en línea). Costa Rica. Consultado
22 nov. 2005. Disponible en: www.chiquita.com/ Discover/images/costaspan.pdf

FAO (Food and Agriculture Organization). 2005. Sistemas de información de los recursos del pienso. D15 Musa x paradisiaca L. (en línea) Consultado 16 nov. 2005. Disponible en: www.fao.org/ag/AGA/AGAP/FRG/afris/ es/Data/14.HTM

LAMMERS, B.; HEINRICHS, A. 2000. Nutrition, feeding, and calves. The response of altering the ratio of dietary protein to energy on growth, feed efficiency, and mammary development in rapidly growing pre-pubertal heifers. Journal of Dairy Science. 83:977-983.

McGUIRK, S.; RUEGG, P. 2005. Enfermedades de terneros y prevención. (en línea). Wisconsin, Estados Unidos. Consultado 28 nov. 2005. Disponible en: www.uwex. edu/milkquality/PDF/calf_diseases_prevention_sp.pdf

NRC (National Research Council). 2001. Nutrient requirements of dairy cattle. 6 ed. Washington D.C. National Academy of Science-National Research Council. 157 p.

OBISPO, N.; LÓPEZ, M.; GARMENDIA, J. 2002. Efecto de la suplementación con harina de pescado sobre la aparición de la pubertad en novillas Holstein. Zootecnia Tropical 20:121-133.

PIRLO, G.; CAPELlETTI, M; MARCHETO, G. 1997. Effects of energy and protein allowances in the diet of prepubertal heifers on growth and milk production. Journal of Dairy Science 80: 730-739.

PULIDO, R. G.; ESPÍNDOLA, S.; LAVERNE, A.; URIBE, H. 2002. Suplementación con maíz molido o roleado al vapor y comportamiento productivo de vacas lecheras en pastoreo primaveral. Archivos de Zootecnia 51: $397-400$.

ROMERO, C. 2005. Manejo de la recría en una explotación de vacuno de leche (I). Madrid, España. Consultado 28 nov. 2005. Disponible en: www.eumedia.es/artículos/ $\mathrm{mg} / 177 \mathrm{~s} \_$vacuno.html

SALVADOR, A. 2002. Midiendo el crecimiento para la crianza de novillas. (en línea). Venezuela. Consultado 
28 nov. 2005. Disponible en: www.ppca.com.ve/vb/ articulos/vb47p60. html

SAS (Statistical Analysis System). 1999. SAS User's Guide: Statistics (Versión 8.2 Ed) SAS Institute Inc. Cary, NC. 373 p.

STEEL, R.; TORRIE, J. 1980. Principles and procedures of statistics. A biometral approach. Second edition. Ed. McGraw-Hill. USA. 633 p.

THOMPSOM, M.; ESPÍNDOLA, S.; URIBE, H.; PULIDO, R. 1999. Efecto de la suplementación de maíz y/o trigo en vacas lecheras con dietas en base a ensilaje de pradera (en línea). XXIV Reunión Anual Sociedad Chilena de Producción Animal. Valdivia, Chile. Consultado 7 dic. 2005. Disponible en: www.inia.cl/remehue//servicios/bromatología/artículos/t14599.pdf.

WATTIAUX, A. 2003. Crianza de terneras del nacimiento al destete. Tasa de crecimiento. (en línea) Consultado 28 nov. 2005. Wisconsin, Estados Unidos. Disponible en: www.babcock.cals.wisc.edu/downloads/de_html/ ch34.es.html 